\title{
Study of the Sensitivity of Optical Properties of Mineral Dust to the Direct Aerosol Radiative Perturbation Using a Global Aerosol Transport Model
}

\author{
Taichu Y. Tanaka, Teruo Aoki, Hiroshi Takahashi, Kiyotaka Shibata, \\ Akihiro Uchiyama and Masao Mikami \\ Meteorological Research Institute, Tsukuba, Japan
}

\begin{abstract}
The sensitivity of optical properties of mineral dust aerosol to its direct radiative effect was investigated using four dust optical datasets (ADEC-1, ADEC-2, OPAC-MD and Dust-Like) with a global aerosol transport model. The annual and global mean direct aerosol radiative perturbation (DARP) by dust at the top of the atmosphere (TOA) can be positive or negative $\left(-0.52\right.$ to $\left.+0.11 \mathrm{~W} \mathrm{~m}^{-2}\right)$ depending on the absorptive property of dust aerosol dataset. The annual and global mean DARP at the surface is negative for all the dust optical datasets $\left(-1.25\right.$ to $\left.-0.27 \mathrm{~W} \mathrm{~m}^{-2}\right)$. If dust is strongly absorptive, DARP at the TOA over oceans at high latitude $\left(>40^{\circ}\right)$ is positive due to the vertical configuration of dust and clouds. The longwave heating at the surface is strong and can exceed the shortwave cooling over desert regions if the absorption of dust is weak. Over a surface with high dust loading, the annual mean shortwave (longwave) DARP can reach $-28 \mathrm{~W} \mathrm{~m}^{-2}\left(+16 \mathrm{~W} \mathrm{~m}^{-2}\right)$. The global mean DARP values both at the TOA and surface are almost proportional to the imaginary part of the refractive index of dust. Seasonal variations of global mean DARP at the TOA significantly depend on the optical properties of dust.
\end{abstract}

\section{Introduction}

Mineral dust aerosol significantly impacts the Earth's climate by scattering and absorbing the solar and terrestrial radiation. Yet, there are still uncertainties in estimating the radiative impact of dust aerosol, as it depends on the characteristics of the dust itself such as atmospheric distribution, optical properties and particle size, and external conditions such as surface albedo, solar zenith angle, and clouds.

The imaginary part of the refractive index $\left(n_{i}\right)$ of dust particles is a key factor in estimating the radiative effect of dust aerosol (Sokolik and Toon 1999; Claquin et al. 1999) because it represents the absorptive properties of the particles. Early studies have reported that dust aerosol is highly absorptive (large $n_{i}$ and low single-scattering albedo). Sokolik and Golitsyn (1993) reported that $n_{i}$ ranges from 0.003 to 0.009 at $\lambda=0.5 \mu \mathrm{m}$. Recent studies, however, reported weak absorptive properties of dust (small $n_{i}$ and high single-scattering albedo) (e.g., Kaufman et al. 2001; Dubovik et al. 2002; Sinyuk et al. 2003; Aoki et al. 2005). In East Asia, Uchiyama et al. (2005) reported weak absorption (small $n_{i}$ ) for Asian dust from sky-radiometer observations in the Aeolian Dust Experiment on Climate impact (ADEC) project (Mikami et al. 2006). In this project, Aoki et al. (2005) developed two dust optical datasets (called ADEC-1 and ADEC-2), which also have less absorptive properties than previously reported datasets.

In this study, we evaluate the sensitivity of the proposed dust optical datasets to the direct radiative effect produced by dust aerosol by a numerical simulation using

Corresponding author: Taichu Y. Tanaka, Meteorological Research Institute, Tsukuba, Japan. E-mail: yatanaka@mrijma.go.jp. @2007, the Meteorological Society of Japan.

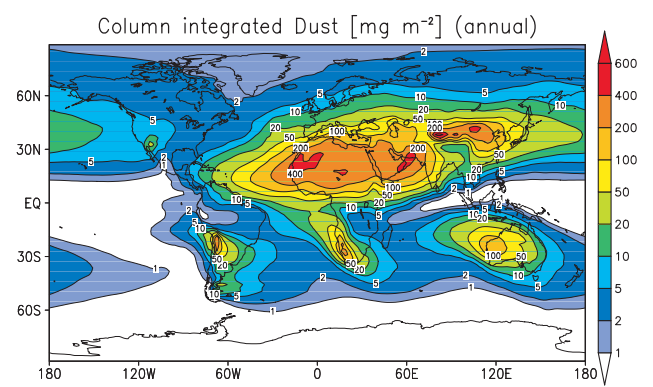

Fig. 1. Simulated annual mean column dust amount in $\mathrm{mg} \mathrm{m}^{-2}$.

an on-line global aerosol transport model, the Model of Aerosol Species IN the Global AtmospheRe (MASINGAR) (Tanaka and Chiba 2005). Previous studies have investigated the sensitivity of optical properties of dust to radiation as a function of the single-scattering albedo (e.g., Miller et al. 2004). This study takes a different approach: we use the refractive index as a more fundamental optical property. Rather than utilizing radiative forcing that is only applied to the external perturbations (e.g., anthropogenic), we focus on the direct aerosol radiative perturbation (DARP), which extends the concept of radiative forcing to any aerosol type (i.e., natural and anthropogenic) (Reddy et al. 2005).

\section{Method}

We used ADEC-1 and ADEC-2 proposed by Aoki et al. (2005), together with two widely used dust optical datasets, Desert Model in the Optical Parameters of Aerosols and Clouds version 3.1 (OPAC-MD) database (Hess et al. 1998), and Dust-Like model (Shettle and Fenn 1979). These four datasets cover the possible range of $n_{i}$ of actual mineral dust (Aoki et al. 2005). ADEC-1 is based on mineralogical methods with three dust aerosol samples collected around Qira $\left(37^{\circ} 01^{\prime} \mathrm{N}, 80^{\circ} 44^{\prime} \mathrm{E}\right)$ in the Taklimakan desert. ADEC-2 was developed by averaging ADEC-1 and OPAC-MD. In the longwave (LW) spectrum $(\lambda>3.0 \mu \mathrm{m})$ in ADEC- 1 and ADEC2 , optical properties in OPAC-MD are adopted. Detailed descriptions of ADEC-1 and ADEC-2 are presented in Aoki et al. (2005). In the shortwave (SW) region, the imaginary parts of the refractive index of these four datasets differ significantly, whereas the real parts are similar (1.48 to 1.53 at $\lambda=0.55 \mu \mathrm{m})$. Table 1 lists the $n_{i}$ of these datasets at $\lambda=$ $0.55 \mu \mathrm{m}$ and $10 \mu \mathrm{m}$. The absorptive properties in the SW spectrum increase in strength from ADEC-1, ADEC-2, OPAC-MD, to Dust-Like. However, in the LW spectrum, the absorptive properties of OPAC-MD, ADEC-1 and ADEC-2 are stronger than Dust-Like.

MASINGAR is a global aerosol transport model coupled with a general circulation model, MRI/JMA 98 GCM (Shibata et al. 1999). MASINGAR treats dust aerosol in ten size classes from 0.2 to $20 \mu \mathrm{m}$ in diameter. The dust emission flux is calculated from the friction velocity, vegetation cover, snow cover, land use type and soil type. 


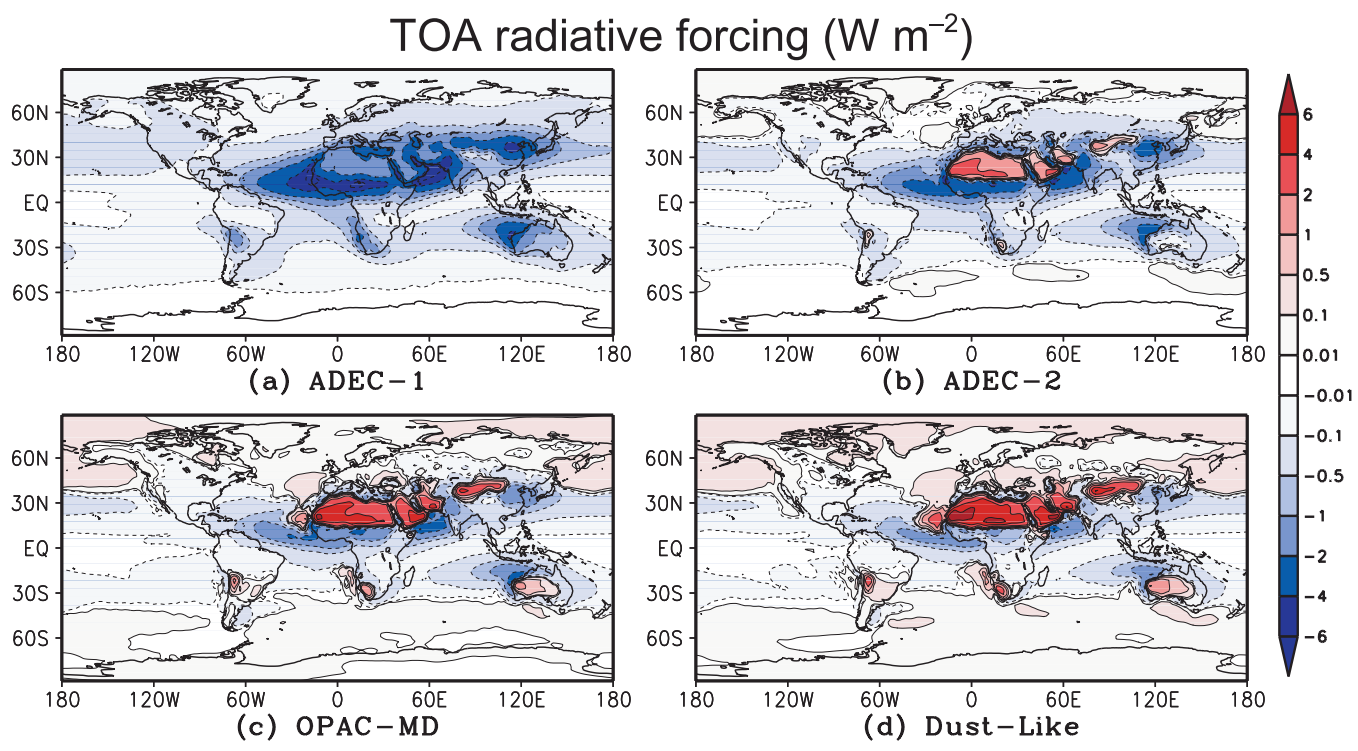

Fig. 2. Annual mean radiative perturbation at the top of the atmosphere in all-sky condition simulated using dust models of (a) ADEC-1, (b) ADEC-2, (c) OPAC-MD and (d) Dust-Like model. Solid (dashed) contours indicate positive (negative) radiative perturbation.

Table 1 . The imaginary part of the refractive index $\left(n_{i}\right)$ and the annual and global mean direct aerosol radiative perturbation by dust with each dust dataset in $\mathrm{W} \mathrm{m}^{-2}$. Numbers in parenthesis are those in the clear sky condition.

\begin{tabular}{ccccccccc}
\hline & $\begin{array}{c}n_{i} \text { at } \\
\text { 0.55 } \mu \mathrm{m}\end{array}$ & $\begin{array}{c}n_{i} \text { at } \\
10 \mu \mathrm{m}\end{array}$ & SW & $\begin{array}{c}\text { TOA } \\
\text { LW }\end{array}$ & Total & SW & $\begin{array}{c}\text { Surface } \\
\text { LW }\end{array}$ & Total \\
\hline ADEC-1 & 0.0004 & 0.5 & $-0.68(-0.92)$ & $+0.16(+0.20)$ & $-0.52(-0.72)$ & $-0.84(-1.07)$ & $+0.57(+0.71)$ & $-0.27(-0.37)$ \\
ADEC-2 & 0.0030 & 0.5 & $-0.38(-0.65)$ & $+0.16(+0.20)$ & $-0.22(-0.45)$ & $-1.22(-1.49)$ & $+0.57(+0.71)$ & $-0.65(-0.79)$ \\
OPAC-MD & 0.0056 & 0.5 & $-0.17(-0.47)$ & $+0.16(+0.20)$ & $-0.01(-0.27)$ & $-1.49(-1.81)$ & $+0.57(+0.71)$ & $-0.92(-1.10)$ \\
Dust-Like & 0.0080 & 0.16 & $+0.03(-0.25)$ & $+0.08(+0.09)$ & $+0.11(-0.16)$ & $-1.54(-1.86)$ & $+0.29(+0.36)$ & $-1.25(-1.50)$ \\
\hline
\end{tabular}

Tanaka and Chiba (2005) described and validated the model in detail with available observations. The parameters in soil size distribution are slightly modified from those used in Tanaka and Chiba (2005), because the previous model produces too much clay fraction (Tanaka and Chiba 2006). The model resolutions are set to a T63 Gaussian horizontal grid (about $1.8^{\circ} \times 1.8^{\circ}$ ) and 30 vertical layers from the surface to a height of $0.4 \mathrm{hPa}$.

The radiative effect of dust is evaluated by incorporating the simulated concentration of dust and its optical properties into the radiation process of the MRI/JMA98 GCM. The radiation process is divided into shortwave $(0.2$ to $5 \mu \mathrm{m}$ in wavelength) and longwave ( 4.5 to $500 \mu \mathrm{m}$ ) spectrums. Scattering in the longwave spectrum is low in compared to absorption, and is omitted. However, Dufresne et al. (2002) have demonstrated that this results in underestimating of longwave forcing so that this omission should be reconsidered in the future. DARP produced by dust is calculated at each time step before climate response, by calling the radiation routine with and without dust and taking the difference in the radiation budget.

We performed a five-year simulation for 1998 to 2002 after a three-month spin-up calculation from a zero dust concentration. The horizontal wind fields were assimilated with the six-hourly data of the reanalysis of the National Centers for Environmental Prediction-Department of Energy Atmospheric Model Intercomparison Project (NCEP-DOE AMIP-II) (Kanamitsu et al. 2002) to obtain a realistic atmospheric field. The sea-surface temperature and ice data were prescribed by the monthly mean HadISST v1.1 data (Rayner et al. 2003). The direct radiative effect due to dust is not fed back to the dynamics in this simulation, as different dust optical datasets produce different heating rates, resulting in different atmospheres, even if the

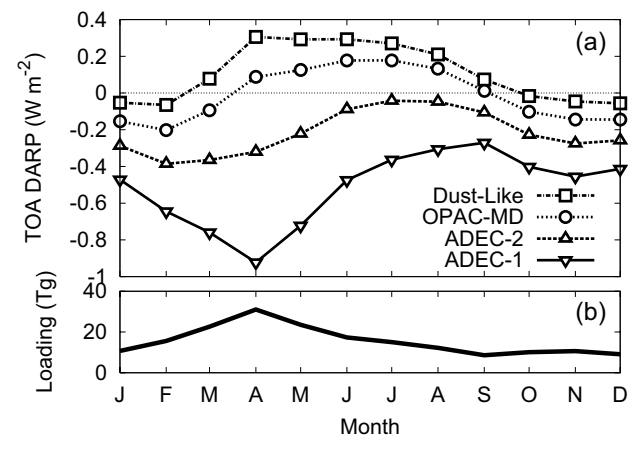

Fig. 3. (a) Monthly and global mean direct aerosol radiative perturbation at the top of the atmosphere. (b) Monthly mean global total dust loading.

assimilation is enforced.

\section{Results and discussion}

Figure 1 depicts the simulated annual mean column dust distribution. The annual total dust emission is 2313 $\mathrm{Tg}$ and the annual mean global atmospheric dust burden is $15.5 \mathrm{Tg}$ in the simulated period. The annual and global mean SW, LW and total DARPs for each dust optical dataset are summarized in Table 1. LW DARPs with ADEC1 and ADEC-2 are the same as for OPAC-MD because the LW optical properties are the same.

Figure 2 presents the simulated annual mean all-sky 


\section{Surface radiative forcing $\left(\mathrm{W} \mathrm{m}^{-2}\right)$}
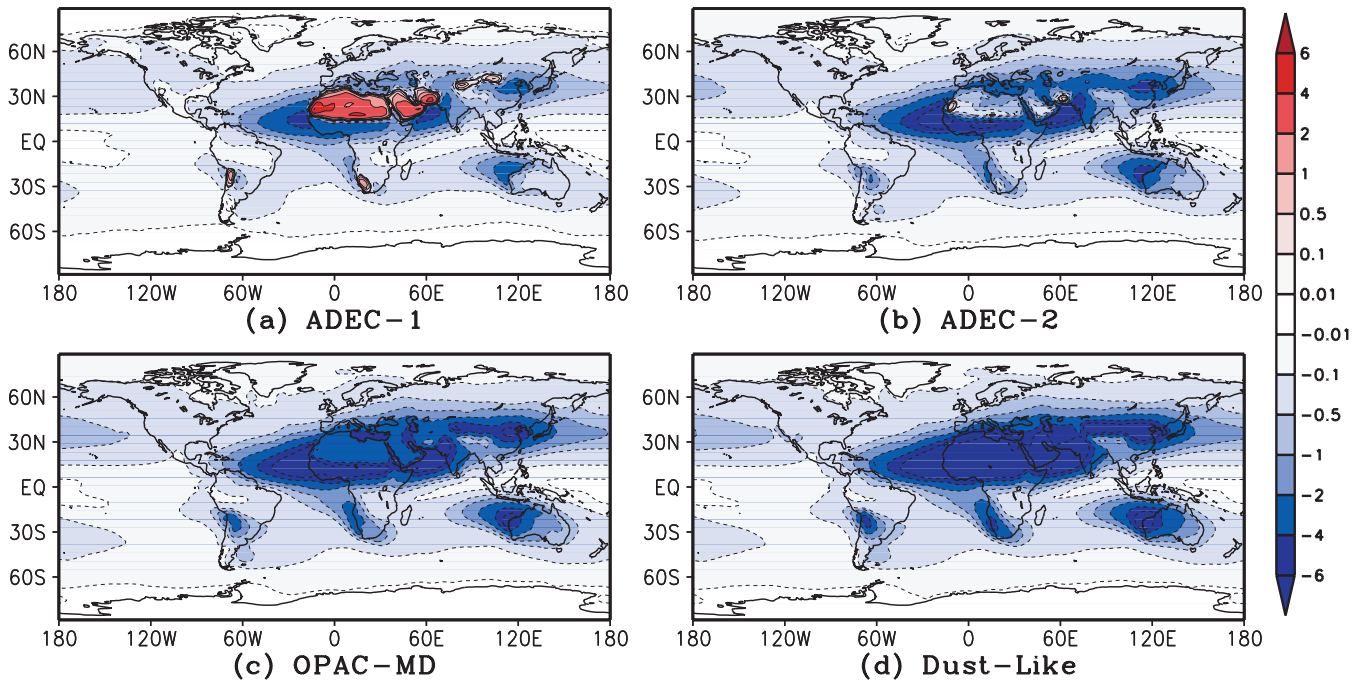

Fig. 4. Same figure as Fig. 2 except at the surface.

DARPs produced by dust at the top of the atmosphere (TOA). DARP at the TOA is predominantly negative with ADEC-1 and ADEC-2, which have weak absorptive properties. In particular, DARP is always negative with ADEC-1. With ADEC-2, OPAC-MD and Dust-Like datasets, DARP is positive over high albedo surfaces such as desert, snow and ice, or regions with frequent lower clouds. The annual and global mean DARP at the TOA under all-sky conditions ranges from -0.52 to $+0.11 \mathrm{~W} \mathrm{~m}^{-2}$, which means the dust could either heat or cool the Earth and the atmosphere depending on its optical properties. When DARP is divided into the SW and LW spectrum, SW DARP is either positive or negative depending on the albedo beneath the dust aerosol, and LW DARP is always positive for every dust optical dataset (see supplemental figure). Over the desert region, SW DARP at the TOA is almost zero in ADEC-2, while it is strongly positive with the OPAC-MD and DustLike datasets. The LW DARP at the TOA is generally weaker than SW DARP, but can reach $+3 \mathrm{~W} \mathrm{~m}^{-2}$ over the regions with large dust loads. The LW DARP for ADEC-1, ADEC-2 and OPAC-MD is about twice as large as that for the Dust-Like dataset. The estimated LW DARP $(+0.08$ to $+0.16 \mathrm{~W} \mathrm{~m}^{-2}$ ) is at the lower bound or smaller than the previous estimates $\left(+0.14\right.$ to $+0.31 \mathrm{~W} \mathrm{~m}^{-2}$ ) (Reddy et al. 2005 ; Woodward 2001; Liao et al. 2004).

DARP at the TOA strongly depends on the relationship of vertical profiles between dust and clouds. While the annual and global mean DARP can be positive under allsky conditions, the clear-sky DARP at TOA is negative for all dust optical datasets $\left(-0.72\right.$ to $\left.-0.16 \mathrm{~W} \mathrm{~m}^{-2}\right)$, which implies that the heating at the TOA by dust is largely attributable to the relationship with clouds. In Fig. 2, the allsky DARP at the TOA over oceans is positive at latitudes above $40^{\circ}$ for absorptive dust optical datasets. This heating at high latitude over ocean is due to the vertical configuration of dust and clouds. The dust tends to be transported to higher altitude when it travels poleward. In contrast, clouds at high latitude tend to reside in the lower level at high latitude. From these factors, dust tends to be positioned above clouds in high latitude, which strengthens the absorption of SW radiation.

Figure 3 presents the monthly averaged global mean DARPs at the TOA for each dust optical dataset, together with the monthly averaged global total dust loading. The seasonal variations of DARP for each dust optical dataset differ significantly. If the absorption of dust is weak (ADEC-1 and ADEC-2), the seasonal variations of DARP are strongly correlated with the total dust loading. When the dust is strongly absorptive (OPAC-MD and Dust-Like), the correlation becomes weak, and the global mean DARP is strongly positive from spring to summer in the northern hemisphere due to the distribution of dust and the strength of the solar radiation. During these seasons, a large amount of dust is emitted from the dry areas and transported to the upper troposphere in the northern hemisphere (Fig. 7 of Tanaka and Chiba 2005). The solar radiation is strong in these seasons over the subtropical regions in the northern hemisphere where the major deserts are located. It is also of note to recognize that the global mean DARP at the TOA is negative even with the dust optical datasets with strong absorptive properties in northern winter. In this season, the heating by dust is weakened by the opposite effects of northern summer; weak solar radiation and suppressed vertical transport of dust.

Figure 4 depicts the annual mean all-sky DARP at the surface for each dust optical dataset. DARP at the surface is always negative for Dust-Like and OPAC-MD, which means the dust cools the surface if the absorption is strong. However, if the absorption is weak (ADEC-1 and ADEC-2), dust heats the surface over desert regions. This is due to the balance between the SW cooling by the absorption of solar radiation and $\mathrm{LW}$ heating by the relaxation of radiative cooling. Over the areas with large dust loads, such as North Africa, the maximum of annual mean SW DARP at the surface can reach from $-17 \mathrm{~W} \mathrm{~m}^{-2}$ (ADEC-1) to $-28 \mathrm{~W} \mathrm{~m}^{-2}$ (Dust-Like) (see supplemental figure), which accounts for 8 to $14 \%$ of the SW radiation budget in the region. The maximum annual mean LW DARP at the surface ranges from $+9 \mathrm{~W} \mathrm{~m}^{-2}$ (Dust-Like) to $+16 \mathrm{~W} \mathrm{~m}^{-2}$ (ADEC-1, ADEC-2, and OPAC), which is half as strong as SW DARP (see supplemental figure). The LW DARP at the surface would be even $15 \%$ greater if we incorporate the scattering of LW in the radiation routine (Dufresne et al. 2002). This result indicates that the LW DARP at the surface is strong and very important. Considering that the SW DARP works only during the daytime, SW cooling and LW heating reduce the radiative difference between day and night, and may affect the regional climate.

The global mean DARP at the TOA increases with increasing absorptive properties of the dust optical dataset, as seen in Table 1. Figure 5 illustrates the relationship between $n_{i}$ at $\lambda=0.55 \mu \mathrm{m}$ and simulated SW DARP. The figure reveals that the DARP at the TOA is almost proportional to $n_{i}$. It also indicates that DARP at the surface 


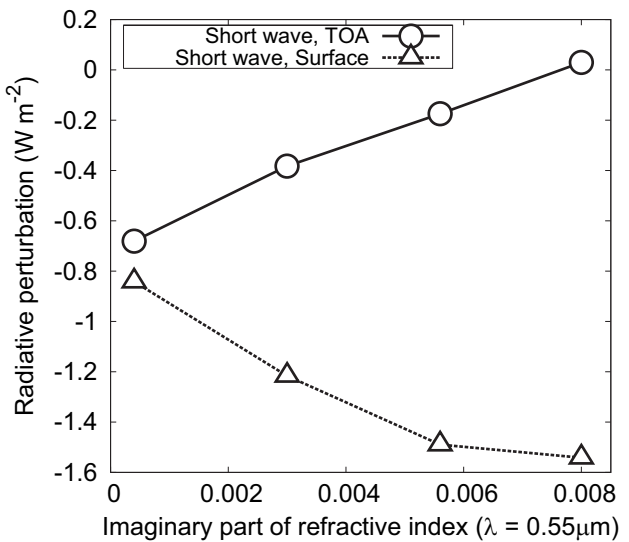

Fig. 5. Relationship between the direct aerosol radiative perturbation and the imaginary part of refractive index $\left(n_{i}\right)$ at the top of the atmosphere and the surface.

decreases with increasing $n_{i}$ of the dust optical datasets.

\section{Concluding remarks}

We have investigated the sensitivity of the optical properties of mineral dust to DARP using four mineral dust optical datasets with the aerosol transport model MASINGAR. The estimated annual and global averaged DARP at the TOA with these datasets can be positive or negative, ranges between -0.52 and $+0.11 \mathrm{~W} \mathrm{~m}^{-2}$, and strongly depends on the absorptive properties of the dust optical dataset. Stronger absorption results in a strongly positive DARP at the TOA, and a strongly negative DARP at the surface. It was found that DARP produced by dust is almost proportional to the magnitude of the imaginary part of the refractive index. Over desert regions, LW heating at the surface can exceed the SW cooling when dust aerosol has low absorption. Seasonal variations of the global mean DARP at the TOA significantly depend on the optical properties of dust. It is strongly correlated with that of total global dust loading if $n_{i}$ is small (ADEC- 1 and ADEC-2) and is not correlated when $n_{i}$ is large (OPAC-MD and Dust-Like). The DARP at the TOA strongly depends on the relationship of vertical profiles between dust and cloud.

The optical properties are assumed to be the same for dust from any source regions in this study; in reality, the optical properties of dust can differ among the dust source regions. Nevertheless, this study clearly demonstrates the possible range of uncertainty of DARP due to the dust optical datasets and the importance of optical properties, especially absorption. It will be necessary to consider the effect of mixing with the other aerosol species, particularly with absorptive pollutants such as soot, because they substantially decrease the single-scattering albedos of dust aerosols.

\section{Acknowledgments}

This study was conducted as a part of the Aeolian Dust Experiment on Climate Impact (ADEC) project funded by the Ministry of Education, Culture, Sports, Science and Technology of Japan.

\section{Comments and supplments}

Annual mean shortwave and longwave radiative perturbations at the TOA and the surface are shown in the supplement 1 .

\section{References}

Aoki, T., T. Y. Tanaka, A. Uchiyama, M. Chiba, M. Mikami, S. Yabuki, and J. R. Key, 2005: Sensitivity experiments of direct radiative forcing by mineral dust using spectrally detailed radiative transfer model. J. Meteor. Soc. Japan, 83A, 315-331.

Claquin, T., M. Schulz, and Y. Balkanski, 1999: Modeling the mineralogy of atmospheric dust sources. J. Geophys. Res., 104, $22243-22256$.

Dubovik, O., B. Holben, T. F. Eck, A. Smirnov, Y. J. Kaufman, M. D. King, D. Tanré, and I. Slutsker, 2002: Variability of absorption and optical properties of key aerosol types observed in worldwide locations. J. Atmos. Sci., 59, 590-609.

Dufresne, J-L., C. Gautier, P. Ricchiazzi, and Y. Fouquart, 2002: Longwave scattering effects of mineral aerosols. J. Atmos. Sci., 59, 1959-1966.

Hess, M., P. Koepke, and I. Schult, 1998: Optical properties of aerosol and clouds: The software package OPAC. Bull. Amer. Meteor. Soc., 79, 831-844.

Kanamitsu, M., W. Ebisuzaki, J. Woolen, S.-K. Yang, J. J. Hnilo, J. Potter, and M. Fiorino, 2002: NCEP-DOE AMIP-II reanalysis (R-2). Bull. Amer. Meteor. Soc., 83, 1631-1643.

Kaufman, Y. J., D. Tanré, O. Dubovik, A. Karnieli, L. A. Remer, 2001: Absorption of sunlight by dust as inferred from satellite and ground-based remote sensing. Geophys. Res. Lett., 28, 14791482.

Liao, H., J. H. Seinfeld, P. J. Adams, and L. J. Mickley, 2004: Global radiative forcing of coupled tropospheric ozone and aerosols in a unified general circulation model. J. Geophys. Res., 109, D16207, doi:10.1029/2003JD004456.

Mikami, M., and Coauthors, 2005: Aeolian dust experiment on climate impact: An overview of Japan-China joint project ADEC. Global and Planetary Changes, 52, 142-172, doi: 10.1016/j.gloplacha.2006.03.001.

Miller, R. L., I. Tegen, and J. Perlwitz, 2004: Surface radiative forcing by soil dust aerosols and the hydrologic cycle. J. Geophys. Res., 109, D04203, doi:10.1029/2003JD004085.

Rayner, N. A., D. E. Parker, E. B. Horton, C. K. Folland, L. V. Alexander, D. P. Rowell, E. C. Kent, and A. Kaplan, 2003: Global analyses of sea surface temperature, sea ice, and night marine air temperature since the late nineteenth century. $J$. Geophys. Res., 108, 4407, doi:10.1029/2002JD002670.

Reddy, M. S., O. Boucher, Y. Balkanski, and M. Schulz, 2005: Aerosol optical depths and direct radiative perturbations by species and source type. Geophys. Res. Lett., 32, L12803, doi:10.1029/ 2004GL021743.

Shettle, E. P., and R. W. Fenn, 1979: Models for the aerosols of the lower atmosphere and the effects of humidity variations on their optical properties. Technical Report AFGL-TR-79-0214, Air Force Geophysics Laboratory.

Shibata, K., H. Yoshimura, M. Ohizumi, M. Hosaka, and M. Sugi, 1999: A simulation of troposphere, stratosphere and mesosphere with an MRI/JMA98 GCM. Pap. Meteor. Geophys., 50, $15-53$.

Sokolik, I. N., and G. Golitsyn, 1993: Investigation of optical and radiative properties of atmospheric dust aerosols. Atmos. Environ., 27A, 2509-2517.

Sokolik, I. N., and O. B. Toon, 1999: Incorporation of mineralogical composition into models of the radiative properties of mineral aerosol from UV to IR wavelengths. J. Geophys. Res., 104, 9423-9444.

Sinyuk, A., O. Torres, and O. Dubovik, 2003: Combined use of satellite and surface observations to infer the imaginary part of refractive index of Saharan dust, Geophys. Res. Lett., 30, 1081, doi:10.1029/2002GL016189.

Tanaka, T. Y., and M. Chiba, 2005: Global simulation of dust aerosol with a chemical transport model, MASINGAR. J. Meteor. Soc. Japan, 83A, 255-278.

Tanaka, T. Y., and M. Chiba, 2006: A numerical study of the contributions of dust source regions to the global dust budget. Global and Planetary Change, 52, 88-104.

Uchiyama, A., A. Yamazaki, H. Togawa, and J. Asano, 2005: Characteristics of aeolian dust observed by sky-radiometer in the Intensive Observation Period 1 (IOP1). J. Meteor. Soc. Japan, 83A, 291-305.

Woodward, S., 2001: Modeling the atmospheric life cycle and radiative impact of mineral dust in the Hadley Centre climate model. J. Geophys. Res., 106, 18155-18166.

Manuscript received 27 November 2006, accepted 10 February 2007 SOLA: http://www.jstage.jst.go.jp/browse/sola/ 